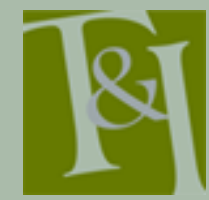

The International Journal for Translation \& Interpreting Research

trans-int.org

\title{
Constructive Alignment in Translator Education: Reconsidering Assessment for Both Industry and Academy
}

\author{
Kobus Marais \\ Senior Lecturer: Language Management and Language Practice \\ Sub-editor (Language Practice): SALALS \\ jmarais@ufs.ac.za
}

DOI: ti.105201.2013.a01

\begin{abstract}
This article follows Toury's example, when he turned the lack of consensus on a definition of translation into his definition or theory of translation, by theorizing the lack of agreement on how to assess translations in translator education. On the basis of two principles of assessment, i.e., constructive alignment and the assessment construct, this article argues that a universal instrument of assessment in translator education is not viable and that, furthermore, the variety of translation theories that are used to conceptualize translation further complicates the matter of assessment. The article then proposes a particular assessment instrument as a case study in the implications of the theoretical stance. The argument against a universal instrument of assessment in translator education also applies to the various forms of translator certification in the translation industry.
\end{abstract}

Keywords: translation studies, translator education, assessment, higher education, translation criticism, translation pedagogy

\section{Introduction}

A significant amount of work has been done on translation assessment ${ }^{1}$ over the last decades (Angelelli \& Jacobson, 2009; González Davies, 2004; Kelly, 2005; Kussmaul, 1995; Malmkjaer, 2004; Nord, 1997; Tennant, 2005). Since Kiraly's first book (1995), this development has in fact been gaining momentum. Much of this work is aimed at incorporating research findings from education sciences regarding teaching, learning, and assessment into the teaching, learning, and assessment of translation. As in the field of translation theory, one seems to find very little agreement in the field of translation assessment, except for an agreement that more work has to be done. One finds volumes in which the lack of agreement, the tension between theory and practice or academy and industry, the lack of reliability of assessment instruments, the lack of rigor in assessment, and scores of other gaps are lamented (for examples, see Angelelli \& Jacobson, 2009; Kiraly, 1995, 2005;

${ }^{1}$ Because terms like 'assessment', 'certification' and 'evaluation' overlap in meaning and are used differently in different education contexts, I state that my focus in this article is assessment, which I define as follows: 'A structured process for gathering evidence and making judgements about an individual's performance in relation to registered national standards and qualifications (SAQA 2001:16). My aim is not to clarify these concepts, so no particular definition of assessment will contribute to my argument. On the contrary, my argument is that, no matter how clearly you define assessment, evaluation or certification, the particular instrument used in whatever you call the process will be theoretically biased. 
Chesterman \& Wagner, 2002; Van de Poel \& Segers, 2007; and the proceedings of the 18th FIT World Conference).

The typical article on translation assessment puts forward a particular view of how "it should be done." Part of the lamentations regarding translator assessment entails the inevitable reference to intellectual opponents who cannot see the light regarding a particular feature deemed important by the author. One example is the work of Van de Poel and Segers (2007), who focus on the requirement that assessment be objective, to the virtual exclusion of all other requirements. Furthermore, in translation, as in most spheres of life, the Western, disciplinary approach to science has led to a schism between theory and practice. This schism is extended to a schism between academic education and the requirements of industry, where, amongst others, the latter complains that the former is too theoretical and that universities do not provide students who "can do the job." The fact that a book to this effect had to be written further underscores the point that a problem exists (Chesterman \& Wagner, 2002).

Rather than proposing yet another assessment rubric that claims to solve either the divide or a particular gap in assessment, the argument in this article is that translation assessment is inevitably grounded in a theoretical view of translation, whether explicitly recognized or not. I am thus taking the same line of argument as Toury's (1995) solution to the definition of translation. If Toury could claim that translation scholars should agree not to define translation, one could extend his line of argument to translation assessment: If there is no universal agreement on the exact nature of an assessment rubric, then turn that disagreement itself into the theory. I therefore argue in this article that the very natures of translation and assessment make it impossible to conceptualize one universally valid method for the assessment of translation.

The article thus aims, firstly, to problematize the issue by indicating why a universal method of translation assessment is not possible or even desirable (as claimed by, for example, Kim (2009)). This approach leads to a conceptualization that is more constructive than merely problematization of the issue. The assessment instrument suggested towards the end of this article does not fill any gap in assessment; rather, it aims to illustrate that, because each assessment instrument assumes a theory of translation, one unified assessment instrument to suit everybody in higher education and the translation industry is neither possible nor desirable. Every reader would thus in principle be able to criticize the suggested assessment instrument as it is aligned with a particular theoretical point of departure and thus, per definition, not universally valid. Put differently, the article will work out the implications of the principle of constructive alignment in assessment in translator education.

\section{Conceptualization}

The principle of constructive alignment states that in order for students to achieve the desired outcomes effectively, the teacher's task is to engage students in learning activities that are likely to result in the students reaching those outcomes (Brown, 2001). This principle means that the curriculum, teaching and learning strategies, and assessment have to be aligned, i.e., have to cooperate with one another and have to reinforce one another to achieve the same goal(s).

In this section, I first argue that constructive alignment, as a principle in assessment, allows me to formulate the theory that a single conceptualization of translation assessment is not viable. In the second part of 
the section, I argue that the multiplicity of theories in translation studies further contribute to the claim that one method of translation assessment is not viable. I do not venture any opinion as to whether or not it may become possible in the future as the future of translation studies is not the aim of this article.

\subsection{Constructive Alignment}

"Assessment guides learning." Scholarly thinking on assessment generally holds this popular tenet as basic to its theoretical case of constructive alignment. Stated in academic language, the "backwash effect" of assessment entails that one can guide learning by assessing in the way you wish students to learn (Biggs, 2002, p. 141; Brown, 2001, p. 4). This idea implies that a theory of assessment is, de facto, informed by a theory of learning, whether tacit or expressed, which is, for its own part, embedded into a philosophy of education. Following Biggs (2002) and Kiraly (2000, 2005), I choose constructivism as the philosophy of learning that underlies the arguments in this article. As Biggs (2002) has argued, most philosophies of learning today accept that learning is not something that is deposited into a learner's mind, but rather something constructed by the learner. In particular, I make use of social constructivism because it offers students the opportunity to learn in the context of a society (Robinson, 2003), which in itself is an effort to bridge the gap between theory and practice (Marais, 2009a).

Within the framework of social constructivism, reflection is the one feature that differentiates deep learning from rote learning (Schön, 1990). Reflection obviously relates to the past, to thinking about what has been done. However, it has its aim in the future, on how things should be (Biggs, 2002) or could be. Concerning the philosophy of social constructivism, Söhnge and Van Niekerk (2005) have put forward the view that education concerns understanding and the application of knowledge in order for the student to become a responsible human being. They make use of aspects of Ricoeur's philosophy, which claims that self-understanding is developed by way of narratives. This means that curriculum implementation is a narrative process between teacher and learner. The implication of their philosophical stance is that a curriculum should have a hermeneutical perspective on education, i.e., a student becomes a human being by means of understanding, explaining, comprehending, and appropriating, which form the basis for selfunderstanding and world-projection and which are constructed by way of narrative (Söhnge \& Van Niekerk, 2005). Teaching and learning thus entail much more than the transfer of knowledge: it should lead to wisdom (Marais, $2009 \mathrm{~b}$ ), i.e., the ethical ability to judge and act in the best interests of a community or a field of study. Developing this idea further, learning is a way of interacting with the world, a way of changing one's concepts of reality. It is not the information itself that brings about this change; rather it is the way in which we structure that information, i.e., the conceptual change that takes place in students that causes the transformation of being and thinking (Biggs, 2002). Within the philosophy of social constructivism, the question is now: what role does assessment play in this process of constructing learning?

Biggs (2002) makes an important point that has to be stressed here: Real understanding is performative; it causes one to act differently. Actually, one could argue that it changes - for the learner - that part of the world that they have been studying; it is deeply, constructively transformative.

Educationists have drawn a distinction between declarative and performative understanding (Biggs, 2002). If, for learning, talking about things is enough, declarative understanding is fine. If changing reality is required, or if one is required to be able to do something with the knowledge acquired, performative understanding is what is needed. In translation education, I 
argue that students need to learn nothing less than performative understanding (which obviously has a declarative basis but is not restricted to it). They need to understand the field in such a way that they are able to operate effectively on the basis of their knowledge. With this point of view, I do not renounce the possibility and even advantages of theoretical knowledge. However, because in most cases we need to educate translators who will function as translators in society, I contend that translator education in which students merely talk about their subject will not suffice. Instead, they have to use and explore the knowledge they have by producing functional translations (see Nord 1997). In order for them to be able to do so, they need a deep, performative understanding of their subject, its history and philosophical roots, and its relationship with translation problems.

Learning thus refers to the systemic engagement between student, teacher, and learning activities (Biggs, 2002). The alignment in a course of study therefore has to be deeper than the mere technical level of the written outcomes being aligned with the instruments of assessment. The approaches to curriculum, teaching and learning, and assessment, all of a philosophical nature, also have to be aligned. If one has chosen constructivism as a philosophy of learning, the curriculum needs to be designed in such a way that it allows for learning experiences that will lead to constructivist learning. It then follows that assessment instruments and assessment itself should be devised in such a way that they assess constructed learning or performative understanding. Once one has established the need for integrated, performative, and deep understanding, the question for assessment is: Does the assessment task allow a student to obtain a good mark or pass on the basis of memorizing facts, or does this assessment instrument measure deep understanding?

If, for example, based on the principle of constructive alignment, it has been decided that the most important outcome for translation students is that they should be able to negotiate ill-structured communication tasks and, by means of wise judgment and written communication skills, facilitate the rendition of print-ready texts that will fulfill their function in a target context, the whole curriculum, teaching and learning activities, and assessment have to work together to achieve that goal. The practical implications of this principle will be illustrated in the next section of this article.

What now becomes important is that in assessment, the categories one uses are defined by quality of understanding, not by number of facts or, in translation, by number of mistakes. The categories one uses in assessment should describe the way a student thinks or performs or should think or perform (Rust, 2002). It then follows logically that grades should tell students something about the nature of their learning, not the amount or quantity thereof, but instead the level or depth. Grades should tell students at what level they have understood the subject matter and this is the reason why deducting marks for mistakes in a translation does not work: it says something about the number of mistakes, but it does not give an indication as to the quality of understanding. What is of critical importance here is that one needs to ensure that the appropriate action verbs for learning are named in the objectives stated in the curriculum, that these same appropriate verbs are elicited in the teaching and learning activities, and that they are embedded in the assessment task (Biggs, 2002). For instance, if one were to decide that one of the objectives of the curriculum would be for students to be able to translate according to the requirements of a brief, ${ }^{2}$ references to brief

\footnotetext{
${ }^{2}$ I use Nord's (1997:30) definition of brief as the information that 'specifies what kind of translation is needed'.
} 
analysis (analyze the brief, translate according to the brief) will feature in the objectives, teaching and learning activities, and the assessment task. In the instrument provided below, the phrase "given the brief" is often referred to.

Without going into detail, the implication of the above is that, for translation assessment, this article prefers criterion-referenced assessment to norm-referenced assessment (Angelelli, 2009). Furthermore, Biggs (2002) points to holistic marking as another principle of assessment relevant to translator education. This preference relates to the principle that the whole artifact that is assessed should meet the standard set, whether this whole is an essay, a translation, or any other assessable artifact. This principle helps in the effort to bridge the gaps in translator education between theory and practice and between academy and industry ${ }^{3}$ through the type of constructive, project-related work Kiraly (2005) has advocated. Institutions of higher education have often been accused of assessing in an academic way, i.e., assessing only one feature of a translation or one part of the process of translation and not the translated product as a whole. Assessment instruments often allow students to perform badly in one aspect of a translation and still obtain a good mark because of the way in which the instrument was structured. As I shall indicate later, the instrument that I propose should solve this problem.

The implications of my argument up to now are that, because there is no one philosophy of education, no one theory of teaching and learning, and no one theory of assessment, creating one ideal instrument for assessing translations is not viable.

\subsection{The Assessment Construct}

Apart from the requirements of constructive alignment, Angelelli (2009) explains that assessment can only take place against the background of an assessment construct. This construct refers to the assessor's understanding of what is to be tested, i.e., what the competencies or skills are, which, in this case, a translator has to be able to perform to be awarded a degree or perhaps professional certification ${ }^{4}$. She indicates that these competencies also have to be broken down into smaller subdivisions and then, importantly, be described in detail. In other words, the assessor has to describe what a good translator is, or what a good translation is, or what a good translation process is. Only then can a particular person, product, or process be measured against that set of standards, i.e., criterion-referenced assessment.

This requirement for translation assessment becomes a problem when one realizes that all conceptualizations of the quality of translators, translations, or translation processes assume some kind of translation theory, whether expressly stated or implicitly assumed. The theoretical nature of these conceptualizations is a problem because assessors with different theoretical assumptions or convictions regarding translation will "measure"

\footnotetext{
${ }^{3}$ The references I make to 'industry' does not refer to the organized translation industry but to institutions such as banks, local government institutions and the media that may be making use of translators and that may need an assessment instrument with which to provide feedback to new employees. Especially in the global South, translation is not necessarily part of a formalized industry, and I thus do not want to venture into the issues of universal sets of standards for the translation industry ${ }^{4} \mathrm{I}$ am following ISO 17024 in using certification. In certain contexts, e.g. South Africa, the term accreditation is used to refer to the same action. As indicated in footnote 1, I am not sure whether the technical distinctions between notions such as assessment and certification are relevant to all contexts around the world and, in particular, whether they are relevant to the point I am trying to make concerning the relativizing effect of constructive alignment and the assessment construct.
} 
different things. Even should they deny the existence at the back of their minds of a particular translation theory, one would be able to point out theoretical bias of some sort in their assessment instrument. Apart from the de facto situation of numerous conflicting or complementary theories of translation, leading scholars of translation also differ in their assessment of the desirability (or lack thereof) of this multiplicity of theory (Toury, 1995; Tymoczko, 2007).

The implication of this difference of opinion is that it is currently not possible to even say whether a universally valid method for translation assessment is desirable at all and whether striving towards it would not be detrimental to the development of translation theory. An example of the way in which the theoretical fragmented nature of the field of study can lead to myopia in assessment is the approach developed by Kim (2009). She problematizes translation assessment due to its "subjective nature" (2009, p.123). She then categorizes what she herself calls "the complex features of translation" (p.152) into the categories of Systemic Functional Linguistics (SFL). Assessing meaning in terms of SFL categories then becomes her answer to the subjectivity of translator assessment. Though it may be true that her assessment criteria are less subjective, it does not follow that they are not also reductionist. In other words, what she is actually assessing is whether her students understand SFL and its application to translation. Kim is thus not solving the problem of subjectivity. She is merely reducing it to the framework of one particular theory, a theory that is biasing her view on the complexity of translations because all theories are reductions. Other articles reflect the same bias, such as Jacobson (2009), which proposes that translation assessment measures pragmatics and then the particular brand of pragmatics that she chooses.

The larger point I wish to make is that the vast number of assumptions one has to make before one can get to assessment, influence the assessment instrument. This article explicates part of the process of getting to a translation assessment instrument, proving that each little choice on the level of instrument reflects a minefield of complex theory on translation behind it. As long as we are in a position in translation theory that claims that we do not want closure on theories (Tymoczko, 2007), that we have disbanded the definition of translation, and that we prefer the current situation of multiple theories, we will not have consensus on assessment.

Once again, determining whether and how long this situation will continue is not part of the aim of this article. Each translation program will assess according to its own theoretical convictions. Various industries will assess to their own convictions while the various academic institutions will have particular convictions influencing their assessment. Should we not put more effort into understanding how and why they differ than into prescribing that they should assess in similar ways?

I close this section by referring to Toury once again. In his view, translation studies have to be descriptive, but the applied branch of translation studies as conceptualized by Holmes has a prescriptive side to it (Toury, 1995). He proposes that practitioners, not scholars, should draw the conclusions from translation studies, which means that academics and practitioners should keep on debating the implications of translation theory and the needs of industry. One could argue that his views represent a schism between theory and practice, but the more important point he is making is that translation studies should feed into applied translation studies. It is thus inevitable that translation assessment is prescriptive and biased according to the (sometimes tacit) theoretical assumptions on which it rests and relative to its context of use, i.e., the academe or industry. 


\subsection{A Constructively Aligned Assessment Instrument for Translator Education}

The assessment instrument described in Table 1 and Figure 1 is presented as a case study in the implementation of the theoretical space created in the previous section. It does not claim to be universally valid. What it does claim is to illustrate openly how a particular theory of translation (functionalist), a particular philosophy of education (constructivist), and a particular assessment construct are aligned to create a particular assessment instrument. The yardstick against which this instrument should be measured is whether it is true to its assessment construct and whether it constructively aligns the assessment with the theory of translation and the philosophy of education. (See also Addendum 2, which contains the criteria for assessment.) It is embedded in a socio-constructivist philosophy of teaching and learning. Furthermore, it is viewed as part of an educational system, which, in its entirety, is constructively aligned. It reflects a particular construct, i.e., a theoretical view of what translation entails, and it is prescriptive, as it prescribes the nature of a good translation.

\begin{tabular}{|l|c|}
\hline 1. Purpose & 10 \\
\hline 1.1 The translation fulfils the purpose for which it was created. & 10 \\
\hline Total & \\
\hline 2. Culture & 10 \\
\hline $\begin{array}{l}\text { 2.1 The translation is adapted to the requirements of the target culture, given } \\
\text { the brief. }\end{array}$ & 10 \\
\hline $\begin{array}{l}\text { 2.2 The translation is adapted to the requirements of the target audience, given } \\
\text { the brief. }\end{array}$ & 20 \\
\hline Total & 5 \\
\hline 3. Text & 5 \\
\hline 3.1 The text type fulfils the requirements of the brief. & 5 \\
\hline 3.2 The target text is structured cohesively. & 15 \\
\hline $\begin{array}{l}\text { 3.3 The style of writing/register conforms to the requirements of the text type } \\
\text { and the brief. }\end{array}$ & 5 \\
\hline Total & 5 \\
\hline 4. Technical aspects & 5 \\
\hline 4.1 The visual appearance of the text is in line with the brief. & 5 \\
\hline 4.2 The spelling is in line with the target language and the brief. & 15 \\
\hline 4.3 The punctuation is in line with the target language and the brief. & \\
\hline Total & 10 \\
\hline 5. Content & 5 \\
\hline 5.1 The information in the target text is adequate, given the brief & 15 \\
\hline 5.2 The information in the target text is relevant, given the brief & \\
\hline Total & 10 \\
\hline 6. Language & 10 \\
\hline 6.1 The use of idiomatic language fulfils the requirements of the target \\
language and the brief
\end{tabular}

Table 1. Assessment Form: Translations

Note. A student who scores less than $70 \%$ in any section will not be able to obtain a distinction for that assignment, i.e., to obtain an overall mark of higher than $74 \%$. For example, a student may obtain a total mark of 78 , which gives the student a distinction. However, in this assessment rubric such a student may receive a maximum of $74 \%$ if for one or more of the six 
sections the student received less than $70 \%$. The reason for this rule is that a translation has to be good in all sections. If it is average in one section, the whole translation cannot be rated as good. Similarly, a student who fails any section also fails the assignment. The requirements for passing are $50 \%$, i.e. 5 or more out of $10,7.5$ or more out of 15 , and 12.5 or more out of 25 . The rationale here is, once again, that a translation that fails on one level fails as a whole.

\section{Purpose}

1.1 Determine/negotiate the viability of the brief.

1.2 Clarify the function/goal/purpose of the translation.

1.3 Determine the motive for the translation.

1.4 Formulate an overall translation strategy, which would help to create a text that would fulfill its purpose.

\section{Culture}

2.1 Analyze the requirements of the target culture.

2.2 Analyze the requirements of the target audience.

2.3 Analyze the time of reception.

2.4 Analyze the place of reception.

\section{Text}

3.1. Determine appropriate text type.

3.2. Determine appropriate subject field.

3.3. Determine appropriate style.

3.4. Determine appropriate register.

\section{Visual appearance}

4.1. Consider visual appearance in terms of brief and target audience/culture.

4.2. Edit for formal layout, consistency, readability, etc.

4.3. Proofread.

\section{Content}

5.1. In terms of the brief and the analyses done under 1, ascertain whether information is accurate/adequate.

5.2. In terms of decisions taken under 1 , decide what information from the source text to utilize in target text.

\section{Language}

6.1. Revise translation in terms of brief analysis.

6.2. Revise translation in terms of source text analysis.

6.3. Revise translation in terms of translation strategy.

6.4. Edit for consistency in language and idiom.

6.5. Edit for consistency in syntax.

6.6. Do research on issues of terminology.

Figure 1. The Translation Process: Checklist

In terms of this approach, the assessment process starts off with setting outcomes for translation courses. Since different courses will have different outcomes as far as level of difficulty or type of translation is concerned, for the sake of the argument, I consider what could be regarded as generic in all translation courses. These module outcomes are aligned to exit-level outcomes, which are what students should be able to do on completion of their qualification and which obviously differ for under-graduate and postgraduate qualifications. Disregarding differences regarding levels of difficulty and specific fields of specialization, the following outcomes occur in all translation modules :

\footnotetext{
${ }^{5}$ I am using the curriculum for undergraduate and postgraduate programs in Language Practice at the University of the Free State, Bloemfontein, South Africa as case study.
} 
- critically reflect on your own translation work and communicate your reflection;

- explain your concept of the process of translation;

- conduct yourself as a budding professional translator;

- function within a social setting of translators; and

- prove that you are able, under supervision, to function effectively in a language practice.

Also, the following objectives are set in all translation modules:

- allow learners to learn unconsciously by doing translation work;

- allow learners to learn reflectively by relating the translation work to aspects of theory;

- provide the necessary opportunity for translation practice;

- model the process of translation for learners;

- enhance learner self-image as professional translators;

- allow learners the opportunity to work in groups and influence each other in all of the above; and

- allow learners to function in a virtual language practice under the coaching of an experienced language practitioner.

The overarching goal of translator education as conceptualized here is thus to help students to become wise translators who are able to reflect on a wide variety of factors before making decisions and who are then able to put those decisions into practice by using their translation skill in order to create functionally (Nord 1997) translated texts. Obviously, as indicated above, the level of difficulty or depth of learning differs in the various modules, as stipulated by the National Qualifications Framework in South Africa (South African Translators' Institute, n.d.). These differences are reflected in differences in the brief provided with each source text, i.e., the difficulty of the translation process that students should be able to negotiate, as well as the level of difficulty of the category of text (e.g., general communicative texts vs. literary texts), and the levels of difficulty pertaining to decisions that are required from students. All of these also relate to the critical cross-field outcomes that are required by policy in South Africa (South African Translators' Institute, n.d.).

The aim is that the assessment instrument should provide the "backwash" predicted by assessment theory, i.e., it should guide students towards the type of understanding and competence that are deemed necessary for them to be wise translators. "Wise" in this sense includes the ability to understand the complexity of a situation, the ability to judge which skill or strategy would solve the problem best, and the skill to put the understanding into practice to solve the problem.

A curriculum aligned with these outcomes provides for a variety of theoretical and practical translation experiences. Translation practice is based on Nord's $(1997,2005)$ functionalist approach, although this is by no means the only theory students are exposed to. Teaching and learning experiences include, amongst others: translation in community-service learning modules; exposure to theories of linguistics, text, and culture; functioning in a virtual language practice; simulated translations; reflective practices; and mentoring classes. Community-service learning, in particular, offers the opportunity to expose students to project-based learning, group work, and the complexity and ill-structured nature of translation problems, as well as the cultural variety found in their context. Students are exposed to community-service learning from their first year, obviously under guidance. 
The assessment instrument above is thus devised to assess the type of learning described in this article. It is divided into six sections, which are structured hierarchically. This structure means that it starts off by assessing the overall translation purpose, followed by culture and target audience, followed by issues of text and document design, then issues of content, and finally issues of language. The hierarchy does not order the sections according to importance; what it does do is reflect the particular decisions students have to make according to the theory in which they are taught to translate. With other theoretical approaches, other divisions and orders are obviously possible. The philosophy behind this structure is a top-down approach, i.e., word choice is determined by sentence structure, which is determined by text, which is determined by culture, which is determined by translation purpose. In this way, the assessment and assessment instrument guide students in learning particular principles of translation. The instrument, in its very format, thus attests to the principles of constructive alignment and the assessment construct.

Furthermore, all categories are assessed as they relate to the brief and the translator's interpretation thereof. To my mind, it has become generally accepted in translation studies that the aim or purpose or function of the translation determines the product. ${ }^{6}$ Thus, culture, text type, style, idiomatic language, and even accuracy are assessed, not in terms of some kind of universal principle or theory, but in terms of the requirements of the brief. As far as quality control in translation is concerned, this instrument assumes that accuracy of information is not the only criterion that makes a translation good. In certain translations, for instance, leaving out a comma can render the whole translation inadequate, while in others, such as literary translation, changing names and dates and even actions would not render the translation inadequate and could, in fact, be necessary. The assessment instrument makes it possible to assess each feature of a translated text and the whole in terms of the brief. It is exactly at this point that this assessment instrument embodies the theoretical notion that translations are measured by their function as required by the brief.

It must be noted here that I have made a conscious decision to use basic principles of functionalist translation theory (Nord, 1997, 2005) as the construct for the assessment instrument. The informed reader will also find reflected in the instrument notions on text linguistics, text theory, principles of document design, etc. My aim is not to force students to make use of a particular theoretical model, but to render a print-ready product that fulfilss its purpose as a translation. I am convinced that, in translation, there are many ways to get the job done and this should not be inhibited by an assessment instrument that forces students into one theoretical conceptualization. One of the aims of higher education is critical thinking, an aim that will not be served by compelling students to use only a particular theory.

On the other hand, I am convinced that being able to reflect using meta-cognitive concepts is the difference between an educated and noneducated translator. Educated translators should, according to this view, be able to reflect on their own work. Therefore, I have connected the assessment instrument, which assesses only the translation product, to a checklist, which relates the product to the translation process. The idea is to relate inadequacies in the product to shortcomings in the process. This process

\footnotetext{
${ }^{6}$ I do not claim that functionalism as a particular theory enjoys this universality, but merely that it has become common wisdom in translation studies that the function of the translation has some role to play.
} 
checklist is based on Nord's theory of the translation process, but does not limit the product to that theory. The theory is only used as a meta-cognitive framework for use in reflecting and communicating about the product. Obviously, not all inadequacies will be related to one or more of the procedural categories, but this fixed checklist will serve two purposes. On the one hand, it will allow for quick and consistent assessing by assessors who are pressed for time. On the other hand, it will relate product and process, practice and theory in a way that will enhance students' learning to the maximum. It does, however, leave room for comments on issues wider than those on the checklist.

Secondly, this assessment instrument assesses qualitatively, not quantitatively. It does not measure the number of mistakes, but it assesses to what extent certain competencies in the product (Table 1) and process (Figure 1) of translation have been acquired. It thus assesses depth of understanding and depth of competence. The competencies of levels of understanding are indicated in a detailed description of the rubric, where the action verbs reflect the expected depth of understanding. This rubric is sent to assessors who assist the department in assessing translations in a wide variety of languages.

Apart from those sections that assist the assessor in assessing the translation in an analytical way, i.e., assessing particular components of the translation, the instrument also assesses the translation as a whole. The provisos in the note beneath Table 1 mean that the product, as a whole, has to be on a certain level before a good grade is granted. Similarly, failure in one part of the product leads to failure of the whole. The parts can be conceptualized as analytically detached, as is done in the instrument, to provide students with formative guidance on their achievements in each aspect. However, the whole dominates and this is built into the assessment instrument.

Once again, this approach allows one to assess the product in terms of the requirements of a translation profession that is mainly interested in the product but still fulfils a pedagogic role by relating it to the process and to theory. It is envisaged that this instrument can be used by industry, too. If agencies would like to assess the product, the instrument is applicable. If employees would like to make sure that they take into account everything that is relevant to the process, they may use the checklist. If an agency has a new apprentice translator, they may use both.

Two notes are necessary regarding the process checklist. First, only checking certain categories without explanation is pointless: assessors are thus expected to provide detailed commentary in the text to point out problem and suggest solutions. Second, the checklist works by way of inference. It does not follow the translation process empirically but instead infers particular process problems from the product. It should be clear to readers that this inference leaves space for differences in interpretation by assessors. However, the aim is not to have a positivist assessment instrument with which to end all discussion. Rather, the checklist could be used as a departure for discussions between lecturers and students, even pointing out to lecturers that their own inference relating to a certain problem was wrong.

The very fact that the instrument assesses both product and process renders it applicable to both industrial and pedagogical settings. Obviously, it assesses in a particular way the translation product and the process by which a translator has come to that product. My argument has been that any assessment instrument does that, especially so-called "objective" instruments used by certification institutions. A detailed analysis of the assessment instrument of the South African Translators' Institute, for which I do not have space in this article, brings to light a linguistic bias in its assumptions about translation or a linguistic theoretical approach to translation. I thus end the 
discussion by questioning the validity of all assessment instruments that do not set out their assumptions or theoretical underpinnings clearly and argue that instruments that do set them out are more valid because they, at least, inform translators of the grounds on which they will be assessed.

\section{Conclusion}

Rather than striving towards a unified assessment instrument for translation or unified conceptualizations with which to assess, I have argued that translation assessments have to be aligned constructively within a curriculum. Assessment instruments are based on theoretical constructs, and as there is no unified translation theory, there can be no universally valid instrument of assessment in translation or translator education. This principle holds for both academe and industry. Therefore, translation assessment instruments that are part of certification examinations must also set out their assumptions and include an explicit translation brief that is available to both the candidate and the assessors.

\section{References}

Angelelli, C. V. (2009). Using a rubric to assess translation ability: Defining the construct. In C. V. Angelelli \& H. E. Jacobson (Eds.), Testing and assessment In translation and interpreting studies (pp. 13-48). Amsterdam: John Benjamins.

Angelelli, C. V., \& Jacobson, H. E. (2009). Testing and assessment in translation and interpreting studies. Amsterdam: John Benjamins.

Biggs, J. B. (2002). Teaching for quality learning in higher education. Buckingham: Open University Press.

Brown, G. (2001). Assessment: A guide for lecturers. Assessment Series 3. Retrieved from 
http://www.heacademy.ac.uk/assets/documents/resources/database/id 3_Assessment_A_Guide_for_Lecturers.rtf.

Chesterman, A., \& Wagner, E. (2002). Can theory help translators? A dialogue between the ivory tower and wordface. Manchester: St. Jerome.

South African Qualifications Authority (SAQA). 2001. Criteria and guidelines for assessment of NQF registered unit standards and qualifications. Retrieved from http://www.saqa.org.za/docs/critguide.assessment/assessment.pdf.

González Davies, M. (2004). Multiple voices in the translation classroom. Amsterdam: John Benjamins.

Jacobson, H. E. (2009). Moving beyond words in assessing mediated interaction: Measuring interactional competence in healthcare settings. In C. Angelelli \& H. Jacobson (Eds.), Testing and assessment in translation and interpreting studies (pp. 49-70). Amsterdam: John Benjamins.

Kelly, D. (2005). A handbook for translator trainers. Manchester: St. Jerome. Kussmaul, P. (1995). Training the translator. Amsterdam: John Benjamins Publishing Company.

Kim, M. (2009). Meaning-oriented assessment of translations: SFL and its application to formative assessment. In C. Angelelli \& H. Jacobson (Eds.), Testing and assessment in translation and interpreting studies (pp. 123-58). Amsterdam: John Benjamins.

Kiraly, D. C. (1995). Pathways to translation: Pedagogy and process. Kent, $\mathrm{OH}$ : Kent State University Press.

Kiraly, D. C. (2000). A social constructivist approach to translator education. Empowerment from theory to practice. Manchester: St. Jerome.

Kiraly, D. C. (2005). Project-based learning: A case for situated translation. Meta 50(4), 1098-1111.

Malmkjær, K. (Ed.). (2004). Translation in undergraduate degree programmes. Amsterdam: John Benjamins.

Marais, K. (2009a). "Welcome to my side of town": Opportunities for teaching and learning by means of service learning in translator education. Journal for Language Teaching 43(1), 100-114.

Marais, K. (2009b). Wisdom and narrative: Dealing with complexity and judgment in translator education. Acta Theologica Supplementum 12, 217-33.

Nord, C. (1997). Translation as a purposeful activity: Functionalist approaches explained. Manchester: St. Jerome.

Nord, C. (2005). Text analysis in translation. Theory, methodology and didactic application of a model for translation-oriented text analysis (2nd ed.). (C. Nord \& P. Sparrow, Trans.). Amsterdam: Rodopi.

Robinson, D. (2003). On becoming a translator. An introduction to the theory and practice of translation (2nd ed.). London: Routledge.

Rust, C. (2002). The impact of assessment on student learning. Active learning in higher education 3(2), 145-58.

SAQA (South African Qualifications Authority). 2001. Criteria and guidelines for assessment of NQF registered unit standards and qualifications. Retrieved from http://www.saqa.org.za/docs/critguide.assessment/assessment.pdf.

South African Translators' Institute. (n.d). Accreditation. Retrieved from http://translators.org.za/sati_cms/index.php?frontend_action=display _text_content\&content_id=1728. 
Schön, D. A. (1990). Educating the reflective practitioner: Toward a new design for teaching and learning in the professions. San Francisco, CA: Jossey-Bass.

Söhnge, W. F., \& Van Niekerk, L. J. (2005). Curriculum as text: Some implications of Ricoeur's hermeneutic theory for curriculum theory. Education as Change 9(1), 168-84.

Tennant, M. (Ed.). (2005). Training for the new millennium: Pedagogies for translation and interpreting. Philadelphia, PA: John Benjamins.

Toury, G. (1995). Descriptive translation studies and beyond. Amsterdam: John Benjamins.

Tymoczko, M. (2007). Enlarging translation, empowering translators. Manchester: St. Jerome.

Van de Poel, C., \& Segers, W. (Eds.). (2007). Vertalingen objectief evalueren: Matrices en ijkpunten. Leuven: Acco. 


\section{Addendum 1: Translation Product}

\section{Purpose}

1.1. The translation is appropriate for the purpose the initiator indicated in the brief. This implies that the source text is not the standard for measuring the success of a translation, but rather whether the target text will fulfill its communicative function in the target context is at stake here. This function always relates to the new context within which the translation will function in the target situation, e.g., medical information in a brochure may need to be translated to be used in a classroom situation at a primary school. No single part of the target text, whether text type, information in the text, culture, or linguistic features, should inhibit the target text from functioning effectively. As a whole, the target text should be functional, i.e., should attain the communicative intent specified in the brief.

10 The translation is excellently functional regarding its new context.

8 The translation is adequately functional regarding its new context.

6 The translation is partly functional regarding its new context.

4 The translation is mostly not functional regarding its new context.

2 The translation is not at all functional regarding its context.

\section{Culture}

2.1. Target culture. The translation is adapted to the cultural environment of the target setting and audience in terms of the requirements of the brief. For culture, this may sometimes imply indigenization and sometimes foreignization. Cultural adaptation should not only concern words and concepts, but also larger cultural trends, e.g., differences in ideology, differences in values, and differences in views on humanity.

5 The translation is excellently adapted to the new culture as required by the brief.

4 The translation is adequately adapted to the new culture as required by the brief.

3 The translation is partly adapted to the new culture as required by the brief.

2 The translation is mostly not adapted to the new culture as required by the brief.

1 The translation is not at all adapted to the new culture as required by the brief.

2.2. Target audience. The translation should be appropriate for the audience as specified by the brief and it has to be written to fit that audience. Factors playing a role in translating for a particular audience are, amongst others, age, level of education, sex, social standing, and the difference between a specialized audience and the general public.

10 The translation is excellently adapted for the needs of the new audience.

8 The translation is adequately adapted for the needs of the new audience.

6 The translation is partly adapted for the needs of the new audience.

4 The translation is mostly not adapted for the needs of the new audience.

2 The translation is not at all adapted for the needs of the new audience. 


\section{Text}

3.1 Text type. The translator has chosen a text type that fulfils the requirements of the brief and the material in the text. The text is written in accordance with the requirements of the type.

5 The text type fits the brief in full.

4 The text type fits the brief adequately.

3 The text type fits the brief partially.

2 The text type mostly does not fit the brief.

1 The text type does not fit the brief at all.

3.2 Cohesion. This section refers to the logical structure and systematic organization of the text, i.e., the clear sequence of ideas. It further refers to the fact that ideas should be related so that the produced text makes sense.

10 The target text is fully coherent and cohesive.

8 The target text is adequately coherent and cohesive.

6 The target text is partially coherent and cohesive.

4 The target text is mostly not coherent and cohesive.

2 The target text is not at all coherent and cohesive.

3.3 Style/register. The brief requires a particular style/register of writing to which the translator should adapt. It relates to the level of formality, the particular way of writing, and the particular conventions of registers.

5 The style/register fits the brief in full.

4 The style/register fits the brief adequately.

3 The style/register fits the brief partially

2 The style/register mostly does not fit the brief.

1 The style/register does not fit the brief at all.

\section{Technical Aspects}

4.1 Visual appearance. The target text should comply with the requirements of the brief as far as visual matters are concerned. This includes font, line spacing, lay-out, formatting, graphics, etc.

5 The target text excellently fulfils the visual requirements of the brief.

4 The target text adequately fulfils the visual requirements of the brief.

3 The target text partially fulfils the visual requirements of the brief.

2 The target text mostly does not fulfill the visual requirements of the brief.

1 The target text does not at all fulfill the visual requirements of the brief.

4.2 Spelling. The spelling should follow the standard requirements of the target language, except if it is specified differently by the brief.

5 The spelling is excellent for the target language and brief.

4 The spelling is adequate for the target language and brief.

3 The spelling is partially sufficient for the target language and brief.

2 The spelling is mostly not appropriate for the target language and brief.

1 The spelling is not at all appropriate for the target language and brief. 4.3 Punctuation. The punctuation should follow the standard requirements of the target language, except if it is specified differently by the brief.

5 The punctuation is excellent for the target language and brief.

4 The punctuation is adequate for the target language and brief.

3 The punctuation is partially sufficient for the target language and brief.

2 The punctuation is mostly not appropriate for the target language and brief.

1 The punctuation is not at all appropriate for the target language and brief. 


\section{Content}

5.1 Adequacy. All necessary information has been translated correctly and accurately to fit the requirements of the brief. Mistranslations, shifts in meaning, and major grammatical errors, which change meaning, fall in this category.

10 The information in the translated text, as required by the brief, is accurate in all respects.

8 The information in the translated text, as required by the brief, is accurate in most respects.

6 The information in the translated text, as required by the brief, is accurate in some respects.

4 The information in the translated text, as required by the brief, is in most respects not accurate.

2 The information in the translated text, as required by the brief, is in no respect accurate.

5.2 Relevance. The information selected from the source text for translation is relevant to the requirements of the brief, i.e., there can be too much or too little information, or irrelevant information could have been included or relevant information could have been left out.

5 The information in the translated text, as required by the brief, is relevant in all respects.

4 The information in the translated text, as required by the brief, is relevant in most respects.

3 The information in the translated text, as required by the brief, is relevant in some respects.

2 The information in the translated text, as required by the brief, is in most respects not relevant.

1 The information in the translated text, as required by the brief, is in no respect relevant.

\section{Language}

6.1 Idiomatic language. The idiomatic nature of the language used in the target text should conform to the requirements of the target language. This refers to collocations, idiomatic expressions, and metaphors, but also to writing style. However, the brief also plays a role, which may override requirements of standard language, e.g., slang or dialects.

10 The language used in the target text excellently meets the requirements of both the target language and the brief.

8 The language used in the target text adequately meets the requirements of both the target language and the brief.

6 The language used in the target text partially meets the requirements of both the target language and the brief.

4 The language used in the target text mostly does not meet the requirements of both the target language and the brief.

2 The language used in the target text not at all meets the requirements of both the target language and the brief.

6.2 Syntax. The syntax should follow the standard requirements of the target language, except if it is specified differently by the brief.

10 The syntax is excellent for the target language and brief.

8 The syntax is adequate for the target language and brief.

6 The syntax is partially sufficient for the target language and brief.

4 The syntax is mostly not appropriate for the target language and brief.

2 The syntax is not at all appropriate for the target language and brief. 
6.3 Terminology. The terminology in the target text should reflect not only the requirements of the brief, but it should also be in line with the target language and the particular register of language, e.g., bureaucratic texts, medical texts, legal texts, etc.

5 The terminology is excellent for the target language and brief.

4 The terminology is adequate for the target language and brief.

3 The terminology is partially sufficient for the target language and brief.

2 The terminology is mostly not appropriate for the target language and brief.

1 The terminology is not at all appropriate for the target language and brief. 


\section{Addendum 2: Translation Process}

Each translation assignment has to be preceded by a decision-making and planning process in which the translator analyses the brief and takes decisions regarding the way in which to carry out the assignment. They do this by writing an essay and by reflecting on their own work by means of writing annotations. This planning phase is a holistic exercise, but for the sake of pedagogy, a number of different aspects to it are indicated. The aim here is solely to help students learn and to see for themselves on which facets they need to do more work.

The second page to the assessment rubric (Translation process: Checklist) refers to aspects of the process of translation. As assessor, you can refer a student to these where they have made mistakes, e. g. if the text was not adapted to the needs of the target audience, it may be because of an incorrect or no brief analysis, a misunderstanding of the intent of the brief, or not editing. The assessor refers the student to the process so that they can better understand why they have made mistakes or why their translation was not successful. 